\title{
Saúde bucal materno-infantil: uma revisão integrativa
}

\section{Maternal and child oral health: an integrative review}

Ana Cláudia Guterres Prestes* Aline Blaya Martins ${ }^{* *}$

Matheus Neves ${ }^{* * *}$

Rose Teresinha da Rocha Mayer ${ }^{* * *}$

\section{Resumo}

Introdução: esta revisão integrativa da literatura tem por objetivo sistematizar conhecimentos que contribuam para formar trabalhadores com saberes e práticas cotidianas convergentes ao SUS e à formação em serviço, nos quais situações, vivências e conteúdos acerca da odontologia possam ser recursos estratégicos a equipes de atenção básica no que diz respeito ao núcleo (saúde bucal), especificamente à linha de cuidado materno-infantil, desde o campo da saúde coletiva. Revisão de literatura: condensaram-se artigos de periódicos disponíveis em bases científicas de dados eletrônicos e documentos oficiais do Ministério da Saúde, para fornecer subsídios ao estabelecimento de um plano de atenção integral à gestante, levando-se em consideração as alterações ocorridas durante esse período. Considerações finais: os documentos avaliados apontam para uma nova realidade, a qual demonstra o trabalho desenvolvido pelos profissionais da saúde bucal, permeado pelas mudanças no SUS e pelo uso sistemático de evidências em relação à técnica e aos materiais odontológicos, e, ainda, o que tal transformação pode promover na conscientização sobre educação em saúde bucal, qualificação no cuidado e empoderamento por parte de profissionais de saúde e das famílias.

Palavras-chave: Odontologia em saúde pública. Saúde bucal. Gestantes.

\section{Introdução}

O princípio da integralidade traduz-se pela atenção à pessoa como um ser integral, não segmentado nos diversos setores ou programas de uma Unidade de Saúde, um contíguo articulado e contínuo de ações e serviços, singular e coletivo ${ }^{1}$. Tal direção para o cuidado emerge com a legislação brasileira, a partir da Constituição Cidadã, no ano de 1988, mas sua consolidação somente ocorre na Lei Federal no 8.080, no ano de 1990, que salienta, como princípios e diretrizes do Sistema Único de Saúde (SUS), a universalização, a equidade, a integralidade, a descentralização e a participação da comunidade ${ }^{2}$.

Assim, a universalidade de acesso aos serviços de saúde em todos os níveis de assistência é um direito dentro do qual se insere a saúde bucal, enfatizada no Relatório da I Conferência Nacional de Saúde Bucal, realizada em 1986, como parte integrante e intrínseca da saúde geral, tendo como objetivo a mudança da prática assistencial na atenção básica ${ }^{3}$.

A base da mudança ocorreu com a incorporação oficial das Equipes de Saúde Bucal (ESB) no Programa de Saúde da Família, em dezembro de 2000, com a publicação da Portaria MS 1.444/2000. A sua implantação reflete-se no comprometimento pactuado do profissional com o usuário, na interdisciplinaridade e na permanente comunicação horizontal da equipe ${ }^{4}$.

Programa de Residência Integrada em Saúde: Atenção Básica em Saúde Coletiva, Centro de Saúde Escola Murialdo - Escola de Saúde Pública do RS, Porto Alegre, RS, Brasil.

Programa de Pós-Graduação em Odontologia da Universidade Federal do Rio Grande do Sul (UFRGS). Doutora em Saúde Bucal Coletiva pela UFRGS, Porto Alegre, RS, Brasil.

*** Professor da Faculdade de Odontologia da Pontifícia Universidade Católica do Rio Grande do Sul (PUCRS). Doutorando em Saúde Bucal Coletiva pela UFRGS, Porto Alegre, RS, Brasil.

**** Programa de Residência Integrada em Saúde: Atenção Básica em Saúde Coletiva. Especialização em Saúde Pública, Escola de Saúde Pública do RS. Mestra em Psicologia Social e Institucional pela UFRGS. Porto Alegre, RS, Brasil. 
Conforme Teixeira, a transformação está no olhar de responsabilização dos profissionais pelo cuidado do usuário, o que requer mais que uma anamnese centrada no procedimento. Determina um diálogo que produz momentos em que o usuário passa a sentir-se confiante e reconhece o profissional como uma referência de cuidado ${ }^{5}$.

O Ministério da Saúde instituiu, em junho de 2000, o Programa de Humanização no Pré-Natal e Nascimento (PHPN), no qual o respeito a esses direitos e a perspectiva da humanização aparecem como elementos fundamentais. Esse programa tem sua base na integralidade da assistência, assegurando a melhoria de acesso da cobertura e da qualidade do acompanhamento pré-natal às gestantes e ao recém-nascido ${ }^{6}$.

Silva e Martelli abordam a estruturação da Política Nacional de Saúde Bucal (Brasil Sorridente) como um marco na ampliação e qualificação do acesso da população às ações de promoção, prevenção, recuperação e reabilitação em saúde bucal ${ }^{7}$. Os autores entendem que esse é um fator fundamental para a saúde geral e para a qualidade de vida e apresentam a Estratégia de Saúde da Família (ESF) como uma estratégia de reestruturação da atenção básica, a partir de um conjunto de ações conjugadas com os princípios do SUS.

A ESF foi organizada tendo, entre seus objetivos, a ampliação do conceito e das práticas de cuidado ${ }^{1}$. Para tanto, faz-se necessário promover mudanças nas atitudes dos profissionais para a integralidade do cuidado ${ }^{8}$.

Descompartimentalizar o conhecimento significa poder cuidar de forma mais responsável. No contexto do SUS, a integração entre as diferentes profissões e as abordagens dos problemas vistos de uma forma integrada são ações que podem promover mudanças no processo de trabalho da equipe, instituindo interdisciplinaridade e benefícios aos usuários ${ }^{9}$.

Seguindo esse intercâmbio de experiências, a saúde bucal passou a integrar as ações dirigidas às linhas de cuidado voltadas a grupos prioritários, dentre os quais, o pré-natal e a primeira infância ${ }^{6}$, implicando, assim, uma forma de cuidar na qual profissionais de saúde realizam consultas coletivas com mães e crianças, com o intuito de promover educação, vigilância e cuidado em saúde . $^{8}$.

Para Finkler, essa perspectiva de vínculo e interdisciplinaridade constituem-se exigência e instrumento potencial que articula diferentes saberes e práticas em torno de uma visão ampla e integral das necessidades e problemáticas da saúde para compor formas de intervenção mais qualificadas, competentes e humanizadas ${ }^{10}$.

Chiesa destaca que valores e culturas no campo da saúde envolvem questões ideológicas, sociais, econômicas e políticas. Indica romper com paradig- mas sem negar a historicidade das profissões, significa modificar o enfoque ainda predominantemente biologicista, curativo, médico centrado e desarticulado das práticas em saúde ${ }^{11}$.

Portanto, este estudo objetiva apresentar o estado da arte em integralidade do cuidado da saúde bucal materno-infantil, no que diz respeito às equipes de saúde bucal da atenção primária à saúde.

\section{Metodologia}

Revisão integrativa constitui um estudo realizado por meio do levantamento bibliográfico, sendo um método que permite uma análise da síntese do conhecimento e a aplicabilidade dos seus resultados na prática. É muito usado no campo da saúde, pois sintetiza as pesquisas disponíveis em determinada temática e direciona a prática, fundamentada em evidência científica. Tem a capacidade de delimitar etapas metodológicas mais precisas para propiciar uma melhor utilização das evidências elucidadas em estudos anteriores. Permite a inclusão de estudos experimentais e não experimentais, ao combinar dados tanto da literatura teórica quanto da empírica ${ }^{12}$.

O plano sistemático para a execução desta revisão integrativa consistiu em quatro etapas. Na primeira etapa, realizou-se o levantamento bibliográfico nas seguintes bases de dados: SciELO; Periódicos Capes, Bireme e Google. Utilizaram-se, como critérios de busca, os documentos publicados no período de 2000 a 2012 e que foram encontrados no modo de "pesquisa avançada", usando cruzamentos com as seguintes palavras-chave: saúde coletiva, saúde bucal, crianças, gestantes, atenção básica, atenção primária em saúde, saúde bucal coletiva, pré-natal odontológico, uso de fármacos em gestantes, cuidados com a saúde bucal do bebê, aleitamento materno e procedimentos clínicos em gestantes. Dentre os documentos encontrados, apenas aqueles que haviam sido publicados na íntegra foram avaliados na etapa seguinte da revisão.

A segunda etapa constituiu-se pela leitura dos resumos constantes dos artigos e documentos previamente selecionados. Na terceira etapa, dentre os resumos levantados, foi feita uma seleção daqueles que contemplavam de 3 a 5 palavras-chave e cuja formulação fosse igual ou aproximada às palavras-chave propostas na busca realizada para este estudo; além disso, o conteúdo apresentado no resumo deveria estar concernente ao objetivo ora proposto. A quarta etapa, então, consistiu na leitura dos textos na íntegra, seguida pela construção de uma tabela com as informações levantadas nesse processo.

Os critérios de inclusão para os artigos foram: ter no mínimo 3 e no máximo 5 combinações entre as palavras-chave e estar publicado na íntegra nos idiomas português e/ou inglês entre os anos de 2000 e 2012 . 


\section{Resultados}

Foram revisadas 27 referências para este estudo, sendo 7 publicações do Ministério da Saúde e 20 artigos científicos (Quadros 1, 2 e 3). A descrição dos resultados, na sistematização do conhecimento e nas tabelas, foi feita de acordo com a relevância. De toda a revisão, apenas dois artigos contemplaram mais de três palavras-chave.

\begin{tabular}{|c|c|c|c|c|c|}
\hline Título & Autores & Ano & $\begin{array}{l}\text { Intervenção } \\
\text { estudada }\end{array}$ & $\begin{array}{c}\text { Considerações/ } \\
\text { temática }\end{array}$ & $\begin{array}{c}\text { Palavras-chave/ } \\
\text { cruzamentos }\end{array}$ \\
\hline $\begin{array}{l}\text { Conhecimento das } \\
\text { gestantes sobre al- } \\
\text { terações bucais e } \\
\text { tratamento odon- } \\
\text { tológico durante a } \\
\text { gravidez }\end{array}$ & BASTIANI et al. & 2010 & $\begin{array}{l}\text { Conhecimento de gestantes } \\
\text { quanto à prevenção, conse- } \\
\text { quências e oportunidade de } \\
\text { tratamento de possíveis altera- } \\
\text { ções bucais desenvolvidas na } \\
\text { gravidez. }\end{array}$ & $\begin{array}{l}\text { As gestantes estão de- } \\
\text { sinformadas sobre } \\
\text { como prevenir as possí- } \\
\text { veis alterações bucais e } \\
\text { não possuem conscien- } \\
\text { tização de que seus pro- } \\
\text { blemas bucais podem } \\
\text { afetar a saúde do bebê. }\end{array}$ & $\begin{array}{l}\text { Saúde bucal, } \\
\text { Gestantes, } \\
\text { Procedimentos clíni- } \\
\text { cos em gestantes. }\end{array}$ \\
\hline $\begin{array}{l}\text { Atenção à saúde } \\
\text { da criança de } 0 \text { a } \\
12 \text { anos }\end{array}$ & $\begin{array}{l}\text { BRASIL. Ministério } \\
\text { da Saúde. Grupo } \\
\text { Hospitalar Concei- } \\
\text { ção. }\end{array}$ & 2009 & $\begin{array}{l}\text { Saúde da criança até os } 12 \\
\text { anos. }\end{array}$ & $\begin{array}{l}\text { Abordagem sobre saúde } \\
\text { geral da criança. }\end{array}$ & $\begin{array}{l}\text { Crianças, } \\
\text { Atenção básica, } \\
\text { Saúde coletiva. }\end{array}$ \\
\hline $\begin{array}{l}\text { Área Técnica de } \\
\text { Saúde da Mulher. } \\
\text { Pré-natal e puer- } \\
\text { pério: atenção } \\
\text { qualificada e hu- } \\
\text { manizada - manu- } \\
\text { al técnico. }\end{array}$ & $\begin{array}{l}\text { BRASIL. Ministério } \\
\text { da Saúde. Secretaria } \\
\text { de Atenção à Saúde. }\end{array}$ & 2005 & $\begin{array}{l}\text { Saúde da mulher, pré-natal e } \\
\text { puerpério. }\end{array}$ & $\begin{array}{l}\text { Manual sobre aspectos } \\
\text { relacionados à saúde } \\
\text { da mulher durante a } \\
\text { gestação e o puerpério, } \\
\text { relacionando aspectos } \\
\text { de prevenção. }\end{array}$ & $\begin{array}{l}\text { Atenção básica, } \\
\text { Saúde coletiva } \\
\text { Gestantes. }\end{array}$ \\
\hline $\begin{array}{l}\text { Departamento de } \\
\text { Atenção Básica. } \\
\text { Saúde bucal. }\end{array}$ & $\begin{array}{l}\text { BRASIL. Ministério } \\
\text { da Saúde. Secretaria } \\
\text { de Atenção à Saúde. }\end{array}$ & 2006 & $\begin{array}{l}\text { O caderno tem como foco evi- } \\
\text { denciar a reorganização das } \\
\text { ações e dos serviços de saúde } \\
\text { bucal no âmbito da atenção } \\
\text { básica. }\end{array}$ & $\begin{array}{l}\text { Manual que aborda po- } \\
\text { líticas de saúde bucal } \\
\text { por ciclos de vida. }\end{array}$ & $\begin{array}{l}\text { Saúde bucal coletiva, } \\
\text { Saúde bucal, } \\
\text { Atenção primária em } \\
\text { saúde. }\end{array}$ \\
\hline $\begin{array}{l}\text { Departamento de } \\
\text { Atenção Básica. } \\
\text { Programa Saúde } \\
\text { da Família. }\end{array}$ & $\begin{array}{l}\text { BRASIL. Ministério } \\
\text { da Saúde. Secreta- } \\
\text { ria de Políticas de } \\
\text { Saúde. }\end{array}$ & 2002 & $\begin{array}{l}\text { Organização da saúde da famí- } \\
\text { lia salientando conceitos como } \\
\text { a participação da comunidade, } \\
\text { a qualidade da assistência e a } \\
\text { integralidade. }\end{array}$ & $\begin{array}{l}\text { Aborda a melhora das } \\
\text { condições da assistên- } \\
\text { cia para constituir-se em } \\
\text { estratégia de mudança } \\
\text { do modelo assistencial. }\end{array}$ & $\begin{array}{l}\text { Atenção básica, } \\
\text { Saúde coletiva, } \\
\text { Saúde bucal coletiva. }\end{array}$ \\
\hline $\begin{array}{l}\text { A formação de } \\
\text { profissionais da } \\
\text { saúde: aprendiza- } \\
\text { gem significativa } \\
\text { à luz da promoção } \\
\text { da saúde }\end{array}$ & CHIESA et al. & 2007 & $\begin{array}{l}\text { A integração ensino-serviço e } \\
\text { a utilização de metodologias } \\
\text { apontadas como estratégias } \\
\text { para o mundo do trabalho e } \\
\text { para as necessidades da popu- } \\
\text { lação, visando ao aprendizado } \\
\text { significativo. }\end{array}$ & $\begin{array}{l}\text { Expõe que competên- } \\
\text { cias e habilidades dos } \\
\text { profissionais de saúde } \\
\text { precisam mudar para } \\
\text { constituir sujeitos } \\
\text { comprometidos com a } \\
\text { busca de equidade do } \\
\text { cuidado, do acesso e da } \\
\text { cidadania. }\end{array}$ & $\begin{array}{l}\text { Atenção básica, } \\
\text { Atenção primária em } \\
\text { saúde, } \\
\text { Saúde coletiva. }\end{array}$ \\
\hline $\begin{array}{l}\text { Percepções de ges- } \\
\text { tantes sobre aten- } \\
\text { ção odontológica } \\
\text { durante a gravidez }\end{array}$ & CODATO et al. & 2008 & $\begin{array}{l}\text { Discutir a percepção de ges- } \\
\text { tantes usuárias do Sistema Úni- } \\
\text { co de Saúde sobre saúde bucal } \\
\text { no período gestacional. }\end{array}$ & $\begin{array}{l}\text { Discute atendimento } \\
\text { odontológico durante a } \\
\text { gravidez e relacionados } \\
\text { a preocupações com se- } \\
\text { quelas à saúde do bebê. }\end{array}$ & $\begin{array}{l}\text { Pré-natal odontológi- } \\
\text { co, } \\
\text { Gestantes, } \\
\text { Saúde bucal. }\end{array}$ \\
\hline $\begin{array}{l}\text { Atenção odonto- } \\
\text { lógica à gestante: } \\
\text { papel dos profis- } \\
\text { sionais de saúde }\end{array}$ & CODATO et al. & 2011 & $\begin{array}{l}\text { Discutir a percepção de mu- } \\
\text { lheres sobre o } \\
\text { papel dos profissionais de saú- } \\
\text { de em relação à atenção odon- } \\
\text { tológica durante a gravidez. }\end{array}$ & $\begin{array}{l}\text { Define que alguns pro- } \\
\text { fissionais de saúde ali- } \\
\text { mentam mitos e medos } \\
\text { sobre atenção odonto- } \\
\text { lógica e saúde bucal no } \\
\text { período gestacional. }\end{array}$ & $\begin{array}{l}\text { Atenção básica, } \\
\text { Saúde bucal coletiva, } \\
\text { Gestantes. }\end{array}$ \\
\hline $\begin{array}{l}\text { Saúde bucal ma- } \\
\text { terno-infantil: um } \\
\text { estudo de repre- } \\
\text { sentações sociais } \\
\text { com gestantes }\end{array}$ & FINKLER et al. & 2004 & $\begin{array}{l}\text { A aproximação entre gestantes, } \\
\text { a odontologia e a equipe mul- } \\
\text { tiprofissional de saúde como } \\
\text { um desafio para o início de um } \\
\text { ciclo de promoção de saúde } \\
\text { bucal. }\end{array}$ & $\begin{array}{l}\text { Discute a inclusão da } \\
\text { Odontologia na assis- } \\
\text { tência pré-natal, no tra- } \\
\text { balho educativo junto } \\
\text { às gestantes, avaliando } \\
\text { o atendimento odonto- } \\
\text { lógico preventivo-rea- } \\
\text { bilitador às consultas do } \\
\text { pré- natal. }\end{array}$ & $\begin{array}{l}\text { Atenção básica, } \\
\text { Pré-natal odontológi- } \\
\text { co, } \\
\text { Gestantes, } \\
\text { Saúde bucal. }\end{array}$ \\
\hline
\end{tabular}

Quadro 1 - Consolidação da revisão integrativa 


\begin{tabular}{|c|c|c|c|c|c|}
\hline Título & Autores & Ano & $\begin{array}{l}\text { Intervenção } \\
\text { estudada }\end{array}$ & $\begin{array}{l}\text { Considerações/ } \\
\text { temática }\end{array}$ & $\begin{array}{l}\text { Palavras-chave/ } \\
\text { cruzamentos }\end{array}$ \\
\hline $\begin{array}{l}\text { Medicamentos na } \\
\text { gravidez e lactação: } \\
\text { guia prático }\end{array}$ & KULAY et al. & 2009 & $\begin{array}{l}\text { Utilização de medicamentos por } \\
\text { gestantes e efeitos sobre o feto. }\end{array}$ & $\begin{array}{l}\text { Avalia a medicalização } \\
\text { na gestação e a necessi- } \\
\text { dade de uma utilização } \\
\text { racional dos medicamen- } \\
\text { tos no pré-natal. }\end{array}$ & $\begin{array}{l}\text { Saúde bucal, } \\
\text { Gestantes, } \\
\text { Fármacos em gestantes. }\end{array}$ \\
\hline $\begin{array}{l}\text { Estratégias educati- } \\
\text { vo-preventivas para } \\
\text { a promoção de saú- } \\
\text { de bucal na primei- } \\
\text { ra infância }\end{array}$ & MAGALHÃES et al. & 2009 & $\begin{array}{l}\text { Apresentar estratégias educativo- } \\
\text {-preventivas à gestante com o in- } \\
\text { tuito de minimizar ações curati- } \\
\text { vas aos seus filhos. }\end{array}$ & $\begin{array}{l}\text { Propõe integralidade do } \\
\text { cuidado a todos os mem- } \\
\text { bros da equipe de saúde. }\end{array}$ & $\begin{array}{l}\text { Saúde bucal, } \\
\text { Saúde bucal do bebê, } \\
\text { Crianças. }\end{array}$ \\
\hline $\begin{array}{l}\text { Manual de anestesia } \\
\text { local }\end{array}$ & MALAMED & 2004 & $\begin{array}{l}\text { Aborda o assunto das anestesias, } \\
\text { seu uso e indicações. }\end{array}$ & $\begin{array}{l}\text { Determina aspectos rele- } \\
\text { vantes ao uso de aneste- } \\
\text { sia e seus efeitos ao orga- } \\
\text { nismo. }\end{array}$ & $\begin{array}{l}\text { Saúde bucal, } \\
\text { Fármacos em gestantes, } \\
\text { Gestantes. }\end{array}$ \\
\hline $\begin{array}{l}\text { Anestésicos locais } \\
\text { em odontologia: } \\
\text { uma revisão de lite- } \\
\text { ratura }\end{array}$ & PAIVA; CAVALCANTI & 2005 & $\begin{array}{l}\text { Compreensão dos aspectos far- } \\
\text { macológicos dos anestésicos. }\end{array}$ & $\begin{array}{l}\text { Mostra as dosagens e } \\
\text { escolhas de anestésicos } \\
\text { conforme indicações de } \\
\text { uso e implicações à saú- } \\
\text { de. }\end{array}$ & $\begin{array}{l}\text { Fármacos em gestantes, } \\
\text { Saúde bucal, } \\
\text { Gestantes. }\end{array}$ \\
\hline $\begin{array}{l}\text { Da fragmentação à } \\
\text { integralidade: cons- } \\
\text { truindo e (des)cons- } \\
\text { truindo a prática } \\
\text { de saúde bucal no } \\
\text { Programa de Saúde } \\
\text { da Família (PSF) de } \\
\text { Alagoinhas }\end{array}$ & SANTOS; ASSIS & 2006 & $\begin{array}{l}\text { Dispositivos que orientam a } \\
\text { atenção integral à saúde bucal: } \\
\text { vínculo, acolhimento, autono- } \\
\text { mia, responsabilização e resolu- } \\
\text { bilidade. }\end{array}$ & $\begin{array}{l}\text { A prática da saúde bucal } \\
\text { é plena de conflitos e } \\
\text { contradições e constitui- } \\
\text {-se em potencial ferra- } \\
\text { menta de mudança nos } \\
\text { processos de trabalho. }\end{array}$ & $\begin{array}{l}\text { Saúde bucal coletiva, } \\
\text { Atenção primária em } \\
\text { saúde, } \\
\text { Saúde bucal. }\end{array}$ \\
\hline $\begin{array}{l}\text { Uso de anestésicos } \\
\text { locais em gestantes }\end{array}$ & SILVA et al. & 2000 & $\begin{array}{l}\text { Os medicamentos na gestação } \\
\text { merecem } \\
\text { atenção pelos riscos potenciais } \\
\text { ao feto } \\
\text { em desenvolvimento. }\end{array}$ & $\begin{array}{l}\text { Considera o uso de mui- } \\
\text { tos medicamentos no pe- } \\
\text { ríodo gestacional. }\end{array}$ & $\begin{array}{l}\text { Fármacos em gestantes, } \\
\text { Gestantes, } \\
\text { Saúde bucal. }\end{array}$ \\
\hline $\begin{array}{l}\text { Revisão integrativa: } \\
\text { o que e como fazer }\end{array}$ & SOUZA et al. & 2010 & $\begin{array}{l}\text { Método de pesquisa que permite } \\
\text { um profundo entendimento do } \\
\text { fenômeno estudado. }\end{array}$ & $\begin{array}{l}\text { Permite a compreensão } \\
\text { mais complexa do tema } \\
\text { de interesse. }\end{array}$ & Revisão integrativa. \\
\hline $\begin{array}{l}\text { Comportamento dos } \\
\text { cirurgiões-dentistas } \\
\text { quanto ao uso de } \\
\text { antibióticos em pa- } \\
\text { cientes gestantes: } \\
\text { riscos e benefícios }\end{array}$ & TIRELLI et al. & 2001 & $\begin{array}{l}\text { Avaliar o comportamento de ci- } \\
\text { rurgiões-dentistas quanto ao uso } \\
\text { de antibióticos em gestantes. }\end{array}$ & $\begin{array}{l}\text { Expõe receios quanto ao } \\
\text { uso de medicações a ges- } \\
\text { tantes. }\end{array}$ & $\begin{array}{l}\text { Gestantes, } \\
\text { Fármacos na gestação, } \\
\text { Procedimentos clínicos } \\
\text { em gestantes. }\end{array}$ \\
\hline $\begin{array}{l}\text { Projeto SB Brasil } \\
2003\end{array}$ & $\begin{array}{l}\text { Brasil. Ministério da } \\
\text { Saúde. Departamento } \\
\text { de Atenção Básica. }\end{array}$ & 2004 & $\begin{array}{l}\text { Avaliação das condições de saú- } \\
\text { de bucal da população brasilei- } \\
\text { ra. }\end{array}$ & $\begin{array}{l}\text { Mostra resultados de le- } \\
\text { vantamento epidemioló- } \\
\text { gico da saúde bucal da } \\
\text { população brasileira. }\end{array}$ & $\begin{array}{l}\text { Saúde bucal coletiva, } \\
\text { Atenção primária em } \\
\text { saúde, Crianças, } \\
\text { Saúde bucal, } \\
\text { Saúde coletiva. } \\
\end{array}$ \\
\hline $\begin{array}{l}\text { Departamento de } \\
\text { Atenção Básica. } \\
\text { Programa Saúde da } \\
\text { Família. }\end{array}$ & $\begin{array}{l}\text { Ministério da Saúde. } \\
\text { Secretaria de Políticas } \\
\text { de Saúde. }\end{array}$ & 2000 & $\begin{array}{l}\text { Reorganização da atenção bási- } \\
\text { ca a partir da regionalização e } \\
\text { hierarquização das ações e dos } \\
\text { serviços. }\end{array}$ & $\begin{array}{l}\text { Estratégia de mudança de } \\
\text { modelo assistencial. }\end{array}$ & $\begin{array}{l}\text { Atenção primária em } \\
\text { saúde, } \\
\text { Atenção básica, } \\
\text { Saúde coletiva. }\end{array}$ \\
\hline $\begin{array}{l}\text { A dimensão cuida- } \\
\text { dora do trabalho de } \\
\text { equipe em saúde } \\
\text { e sua contribuição } \\
\text { para a odontologia }\end{array}$ & TEIXEIRA & 2006 & $\begin{array}{l}\text { Analisa o processo de trabalho } \\
\text { em saúde de uma equipe mul- } \\
\text { tiprofissional na perspectiva do } \\
\text { cuidado e sua contribuição ao } \\
\text { cotidiano. }\end{array}$ & $\begin{array}{l}\text { Desempenho do dentista } \\
\text { na produção de vínculo } \\
\text { e responsabilização, de } \\
\text { modo a influenciar os as- } \\
\text { pectos da prática odonto- } \\
\text { lógica. }\end{array}$ & $\begin{array}{l}\text { Saúde bucal, } \\
\text { Saúde bucal coletiva, } \\
\text { Atenção básica. }\end{array}$ \\
\hline $\begin{array}{l}\text { Programa de Huma- } \\
\text { nização no Pré-Na- } \\
\text { tal e Nascimento } \\
(\mathrm{PHPN})\end{array}$ & $\begin{array}{l}\text { Brasil. Ministério da } \\
\text { Saúde. Secretaria de } \\
\text { Políticas de Saúde. }\end{array}$ & 2009 & $\begin{array}{l}\text { Baseado em análises de neces- } \\
\text { sidades de atenção específica à } \\
\text { gestante, ao recém-nascido e à } \\
\text { mulher no período pós-parto. }\end{array}$ & $\begin{array}{l}\text { Adotar medidas que as- } \\
\text { segurem a melhoria do } \\
\text { acesso, da cobertura e } \\
\text { da qualidade do acom- } \\
\text { panhamento pré-natal, } \\
\text { da assistência ao parto, } \\
\text { puerpério. }\end{array}$ & $\begin{array}{l}\text { Pré-natal odontológico, } \\
\text { Gestantes, } \\
\text { Crianças. }\end{array}$ \\
\hline
\end{tabular}

Quadro 2 - Consolidação da revisão integrativa 


\begin{tabular}{|c|c|c|c|c|c|}
\hline Título & Autores & Ano & $\begin{array}{c}\text { Intervenção } \\
\text { estudada }\end{array}$ & $\begin{array}{c}\text { Considerações/ } \\
\text { temática }\end{array}$ & $\begin{array}{c}\text { Palavras-chave/ } \\
\text { cruzamentos }\end{array}$ \\
\hline $\begin{array}{l}\text { Promoção em saú- } \\
\text { de bucal para ges- } \\
\text { tantes: revisão lite- } \\
\text { ratura }\end{array}$ & SILVA; MARTELLI & 2009 & $\begin{array}{l}\text { Abordagem do conhecimen- } \\
\text { to sobre transmissibilidade das } \\
\text { doenças bucais, identificando } \\
\text { riscos à saúde do binômio mãe- } \\
\text {-bebê. }\end{array}$ & $\begin{array}{l}\text { O acesso à consulta odon- } \\
\text { tológica na Estratégia de } \\
\text { Saúde da Família e a incor- } \\
\text { poração de hábitos orais e } \\
\text { práticas de prevenção. }\end{array}$ & $\begin{array}{l}\text { Saúde bucal, } \\
\text { Gestantes, } \\
\text { Crianças. }\end{array}$ \\
\hline $\begin{array}{l}\text { O acesso de gestan- } \\
\text { tes ao tratamento } \\
\text { odontológico }\end{array}$ & MOIMAZ et al. & 2007 & $\begin{array}{l}\text { Verificar se gestantes foram ou } \\
\text { não submetidas à assistência } \\
\text { odontológica durante a gravidez } \\
\text { e os motivos que dificultaram o } \\
\text { acesso a esse serviço. }\end{array}$ & $\begin{array}{l}\text { Necessidade de gestantes } \\
\text { serem priorizadas nos pro- } \\
\text { gramas de atenção odon- } \\
\text { tológica. Os profissionais } \\
\text { devem promover o apren- } \\
\text { dizado } \\
\text { sobre saúde bucal na gra- } \\
\text { videz. }\end{array}$ & $\begin{array}{l}\text { Gestantes, } \\
\text { Saúde bucal, } \\
\text { Atenção primária em } \\
\text { saúde. }\end{array}$ \\
\hline $\begin{array}{l}\text { Educação em saúde } \\
\text { como estratégia de } \\
\text { promoção de saúde } \\
\text { bucal em gestantes }\end{array}$ & REIS et al. & 2010 & $\begin{array}{l}\text { Discutir a importância da edu- } \\
\text { cação em saúde como estratégia } \\
\text { de promoção de saúde bucal no } \\
\text { período gestacional. }\end{array}$ & $\begin{array}{l}\text { Mulher consciente da im- } \\
\text { portância de seu papel na } \\
\text { manutenção de hábitos de } \\
\text { saúde bucal no meio fami- } \\
\text { liar atua como agente mul- } \\
\text { tiplicador de informações } \\
\text { preventivas e de promoção } \\
\text { de saúde bucal. }\end{array}$ & $\begin{array}{l}\text { Saúde bucal coletiva, } \\
\text { Gestantes, } \\
\text { Atenção primária em } \\
\text { saúde. }\end{array}$ \\
\hline $\begin{array}{l}\text { Atendimento odon- } \\
\text { tológico em gestan- } \\
\text { tes: uma revisão da } \\
\text { literatura }\end{array}$ & POLETTO & 2008 & $\begin{array}{l}\text { Tratamento odontológico duran- } \\
\text { te a gravidez, possibilitando } \\
\text { esclarecimentos para basear as } \\
\text { condutas clínicas em evidências } \\
\text { científicas. }\end{array}$ & $\begin{array}{l}\text { O atendimento precisa } \\
\text { cumprir pré-requisitos para } \\
\text { que sejam selecionados } \\
\text { os agentes mais seguros, } \\
\text { limitando a duração do } \\
\text { tratamento e minimizando } \\
\text { dosagens, fundamental para } \\
\text { uma terapia segura. }\end{array}$ & $\begin{array}{l}\text { Gestantes, } \\
\text { Fármacos em gestação, } \\
\text { Procedimentos clínicos } \\
\text { em gestantes, } \\
\text { Saúde bucal. }\end{array}$ \\
\hline $\begin{array}{l}\text { Prescrição medi- } \\
\text { camentosa no tra- } \\
\text { tamento odontoló- } \\
\text { gico de grávidas e } \\
\text { lactantes }\end{array}$ & AMADEl et al. & 2011 & $\begin{array}{l}\text { O cirurgião-dentista, como pro- } \\
\text { fissional da saúde, deve avaliar a } \\
\text { necessidade, a eficácia e a rela- } \\
\text { ção risco/benefício dos medica- } \\
\text { mentos que podem ser prescritos } \\
\text { para gestantes. }\end{array}$ & $\begin{array}{l}\text { O cirurgião-dentista deve } \\
\text { prescrever de forma racio- } \\
\text { nal e responsável, com o } \\
\text { intuito de evitar os efeitos } \\
\text { indesejáveis que podem ser } \\
\text { causados pelo uso dos me- } \\
\text { dicamentos. }\end{array}$ & $\begin{array}{l}\text { Gestantes, } \\
\text { Fármacos em gestantes, } \\
\text { Saúde bucal do bebê. }\end{array}$ \\
\hline $\begin{array}{l}\text { Saúde bucal e cui- } \\
\text { dado odontológico: } \\
\text { representações } \\
\text { sociais de mães usu- } \\
\text { árias de um serviço } \\
\text { público de saúde }\end{array}$ & DOMINGUES et al. & 2008 & $\begin{array}{l}\text { O que pensam as gestantes sobre } \\
\text { saúde bucal e tratamento odon- } \\
\text { tológico. }\end{array}$ & $\begin{array}{l}\text { A humanização no atendi- } \\
\text { mento } \\
\text { e a competência do profis- } \\
\text { sional apareceram como as- } \\
\text { pectos importantes à deci- } \\
\text { são de ir ou não ao dentista. }\end{array}$ & $\begin{array}{l}\text { Saúde bucal coletiva, } \\
\text { Atenção básica, } \\
\text { Gestantes. }\end{array}$ \\
\hline
\end{tabular}

Quadro 3 - Consolidação da revisão integrativa

Os assuntos mais relevantes levantados foram:

- a estruturação da ESF como marco da ampliação e qualificação de acesso à saúde;

- a organização da ESF com o objetivo de ampliação dos conceitos e das práticas de cuidado, visando à integralidade do cuidado;

- mudança no modelo assistencial, reconhecendo o profissional da saúde de qualquer área como referência no cuidado;

- necessidade de mudança de comportamento dos profissionais na prática da atenção integral à saúde;

- necessidade de romper paradigmas e tentar modificar o modelo biologicista, médico centrado e desarticulado do cuidado em saúde;

- a universalidade e a integralidade do cuidado às gestantes, implicando melhor adesão e consequentes mudanças de comportamento relacionadas à saúde bucal;
- necessidade de um olhar integral e humanizado, na vigilância do cuidado continuado à gestante;

- dificuldades na mudança de hábitos, tanto por parte dos profissionais quanto dos usuários;

- promoção de saúde e intervenção qualificada e humanizada, gerando a aproximação de profissionais e gestantes por meio do estabelecimento de vínculo;

- bons hábitos da mãe e suas implicações em medidas preventivas relacionadas com a saúde do bebê;

- o papel da mãe como agente multiplicadora do conhecimento no núcleo familiar;

- necessidade de mudança nos padrões e nas condições de saúde bucal durante a gestação; 
- desmitificação e educação de gestantes sobre procedimentos clínicos que podem ser feitos com segurança na gravidez;

- o uso de fármacos e de manobras técnicas, de acordo com o princípio de uso racional, sempre ponderando riscos e benefícios à mãe e ao feto.

\section{Discussão}

Bastiani aborda a importância da saúde bucal durante o período gestacional e a conscientização acerca das alterações bucais que podem ocorrer durante a gestação e do modo como podem ser prevenidas. É nesse contexto que as mulheres estão propícias a receber novos conhecimentos, sendo mais receptivas quanto às mudanças de determinados padrões capazes de ter implicações positivas sobre a saúde do bebê ${ }^{13}$.

Moinaz destaca que gestantes são consideradas pacientes especiais, por representarem um grupo de risco para doenças bucais e também por apresentarem alterações físicas, biológicas e hormonais que culminam por criar condições adversas no meio bucal, sendo importante a educação com a finalidade de propor mudanças no comportamento social ${ }^{14}$.

Considerando que a gestação é um momento favorável a desenvolver novos comportamentos de saúde, a ESF propõe-se a acompanhar gestantes e crianças na primeira infância, pois se acredita que, se informações essenciais de saúde bucal forem incorporadas ao trabalho de campo das equipes de saúde, pode haver uma valorização do cuidado em saúde bucal e, portanto, estímulo à adesão e à procura por cuidados odontológicos pelas gestantes/ mães ${ }^{2,15}$.

A gestação é um acontecimento fisiológico, cujas alterações biológicas demandam dos profissionais de saúde o conhecimento adequado para uma abordagem diferenciada. $\mathrm{O}$ estado da saúde bucal durante a gestação tem relação com a saúde geral da gestante e pode influenciar na saúde geral e bucal do bebêe $\hat{e}^{6,8}$.

O contato, ainda durante o pré-natal ou logo após o nascimento da criança, entre a equipe de saúde e os pais, representa uma oportunidade para estimular escolhas saudáveis, permitindo que pais e cuidadores sejam orientados ao desenvolvimento de ações domésticas, como a realização de uma boa higienização bucal, propondo acostumar a criança com a manipulação da boca e a sensação de "boca limpa"16.

Desse modo, a sensibilização da equipe multiprofissional a respeito da saúde bucal materno-infantil instrumentaliza e, consequentemente, promove outras formas de cuidado dos profissionais na prática da atenção integral à saúde bucal ${ }^{6,8}$.

Além disso, ao pensar na família como um espaço primário de relacionamento social, verifica-se que as mulheres e mães exercem certa influência em questões relacionadas à saúde, atuando como agentes produtoras e multiplicadoras de conhecimentos ${ }^{10}$.
Conforme Codato e colaboradores, os benefícios de boas práticas de saúde, certamente, se estenderão ao futuro bebê, por meio da adoção de hábitos alimentares adequados e de medidas preventivas, minimizando a possibilidade do surgimento de patologias na criança ${ }^{17}$.

Salienta-se que nem sempre é possível resolver uma necessidade apresentada, tampouco desmitificar hábitos e crenças arraigadas de anos, mas é sempre possível cuidar, escutar e contribuir para a saúde ${ }^{18}$.

A gestante passa, então, a ser encarada como uma promotora da saúde, pois, quando bem informada, torna-se elemento chave na quebra da cadeia da transmissibilidade da cárie dentária ${ }^{14}$.

Existem algumas confusões e alguns mitos a respeito de manejo e tratamento relacionados com a saúde bucal de gestantes, os quais também serão abordados nesta revisão de literatura integrativa.

Os hormônios sexuais femininos têm um importante papel na progressão das alterações periodontais em gestantes. Sendo assim, tecidos periodontais tornam-se suscetíveis a mudanças inflamatórias induzidas por placa dentária diante de alterações hormonais da gestação $0^{13}$. No entanto, raspagem supragengival e controle de placa com higiene bucal reforçada podem ser realizados durante qualquer trimestre, uma vez que gengivite na gravidez é a condição mais comum, pois a gengiva torna-se vascularizada, edemaciada e sensível ${ }^{2}$.

Já a incidência da cárie dentária não está diretamente ligada ao período gestacional, mas a fatores como a menor capacidade estomacal, levando a que a gestante diminua a quantidade de ingestão de alimentos durante as refeições e aumente sua frequência. Essa atitude pode resultar em um incremento de carboidratos na dieta, o que, associado ao descuido com a higiene bucal, aumenta o risco de cárie ${ }^{13}$.

As radiografias odontológicas que forem necessárias podem ser feitas durante a gravidez e em qualquer trimestre da gestação, desde que medidas protetoras sejam tomadas (uso de filmes ultrarrápidos e avental de chumbo $)^{19}$. Uma exposição radiográfica não afeta o desenvolvimento fetal, e para existir a possibilidade de malformação ou aborto espontâneo, é necessária uma exposição de 5 rads, equivalendo uma tomada radiográfica intrabucal a 0,01 milirads de radiação ${ }^{13}$.

A prescrição de fluoretos por via oral em gestantes é um fato bastante contraditório, pois seu efeito protetor relacionado à cárie é predominantemente tópico, ocorrendo, sobretudo, na interface placa/ esmalte, por meio da remineralização de lesões de cárie iniciais e da redução da solubilidade do esmalte dentário. Assim, a prescrição de medicamentos fluoretados no período pré-natal não traz qualquer benefício que justifique sua indicação $0^{13}$.

Já em relação ao uso de anestésicos, aspectos como quantidade da droga administrada, técnica anestésica, ausência/presença de vasoconstritor e os efeitos citotóxicos necessitam ser observados ${ }^{20}$. A lidocaína é o anestésico mais apropriado para as gestantes. Prilocaína e articaína precisam ser evitadas, 
pela possibilidade de levarem à meta-hemoglobinemia tanto na mãe quanto no feto ${ }^{21}$.

Conforme Poletto, sem vasoconstritor o anestésico pode não ser eficaz, e seu efeito pode passar mais rapidamente. A dor resultante pode levar a gestante ao estresse, ocasionando liberação de catecolaminas endógenas em quantidades muito superiores àquelas contidas em tubetes anestésicos e, consequentemente, mais prejudiciais ${ }^{20}$.

A prescrição de medicamentos é parte integrante do processo de assistência à saúde, e o princípio que orienta a escolha da terapêutica a ser utilizada em gestantes é baseado na relação risco-benefício para o feto e a mãe ${ }^{22}$. Dessa maneira, durante os três primeiros meses ( $18^{\circ}$ ao $60^{\circ}$ dia) de gestação, ocorre a organogênese. Nessa fase, os órgãos do feto estão em desenvolvimento, sendo considerado um período crítico para a suscetibilidade teratogênica ${ }^{23}$.

Os fármacos durante a lactação são administrados de modo conservador, e a quantidade total do medicamento que o lactente pode receber por dia por meio do leite materno deve ser menor do que aquela considerada como dose terapêutica, administrada de 30 a 60 minutos após a amamentação ou de 3 a 4 horas antes da próxima mamada. Tal intervalo de tempo permite a depuração de muitos fármacos do sangue materno ${ }^{23}$.

Durante a gestação, as penicilinas podem ser utilizadas, quando necessário, com segurança em qualquer período, pois são os antibióticos mais indicados na prevenção e no tratamento de infecções maternas e intrauterinas ${ }^{24}$. Dentro do grupo das penicilinas, as mais recomendadas são as biossintéticas, como as fenoximetilpenicilinas, e as semissintéticas de largo espectro, como as ampicilinas e as amoxicilinas. As tetraciclinas estão totalmente contraindicadas na gravidez, pois atravessam com facilidade a placenta e são depositadas nos ossos e dentes durante os períodos de calcificação ativa, podendo causar malformações no esmalte dentário ${ }^{25}$.

Tirelli sugere a prescrição do estearato de eritromicina e das cefalosporinas como opção somente nos casos de pessoas alérgicas às penicilinas ${ }^{24}$. Quando houver necessidade curativa, o período mais seguro para o tratamento odontológico é o segundo trimestre da gestação ${ }^{6,8,13}$.

Poletto pondera que, apesar de se priorizar a prevenção, quando houver necessidade curativa, o tratamento pode ser instituído, uma vez que os problemas da cavidade bucal podem ter influência tanto para a mãe quanto para o feto, especialmente quando se compromete a nutrição e contribui-se para a infecção e disseminação de patógenos no sangue ${ }^{20}$.

Os casos que necessitam de tratamento de urgência são solucionados independentemente do período gestacional ${ }^{10}$. Exodontias não complicadas, tratamentos periodontal e endodôntico, restaurações dentárias, instalação de próteses e outros tipos de procedimentos são realizados com segurança, de preferência, no segundo trimestre ${ }^{19}$. Tratamentos seletivos como as reabilitações bucais extensas e as cirurgias mais invasivas podem ser programados para o período de pós-parto ${ }^{26}$.
A articulação dessa gama de saberes que resulta da aproximação entre gestantes, profissionais da odontologia e os demais componentes da equipe multiprofissional parece ser um desafio para o início de um ciclo de promoção de saúde bucal promissor, para o qual são relevantes a dimensão educativa das práticas de saúde e o trabalho pré-natal interdisciplinar $^{10,27}$.

\section{Considerações finais}

A Promoção de Saúde Bucal é parte da Saúde Integral da gestante e do bebê. $\mathrm{O}$ enfoque da educação em saúde e da integralidade precisa contribuir para a extinção de mitos que permeiam a gestação e o atendimento odontológico, bem como para a transformação efetiva da gestante em agente educador precoce à saúde das futuras gerações.

A qualificação da ESF, em relação à abordagem da saúde bucal como parte do cuidado integral à saúde materno-infantil, constitui um grande desafio ao fortalecimento da atenção básica, à saúde bucal coletiva e à consolidação do SUS. Apesar dos avanços da saúde bucal, estamos ainda longe de garantir a universalidade, a equidade e a integralidade das ações desse campo, como pressupõe o ideal do SUS.

Acredita-se que a questão da integralidade representa um desafio aos profissionais da saúde, porque propõe um rompimento de formas cristalizadas de se construir o cuidado à saúde materno-infantil, no que tange tanto ao autocuidado quanto ao cuidado recebido por parte dos profissionais, uma vez que há um confronto quanto a padrões de intervenção médico-odontológica que já fazem parte das crenças e/ou tradições.

Assim sendo, os documentos avaliados parecem apontar para uma nova realidade que demonstra que o trabalho que vem sendo desenvolvido pelos profissionais da saúde bucal, permeado pelas mudanças do SUS ao longo de décadas e pelo uso sistemático de evidências em relação à técnica e aos materiais odontológicos, poderá vir a promover conscientização sobre educação em saúde bucal, qualificação no cuidado e empoderamento por parte de profissionais de saúde e das famílias.

\section{Abstract}

Introduction: this integrative literature review aims to systematize knowledge that helps raising workers with daily knowledge and practices converging to the SUS (Unified Health System) and to service training, in which situations, experiences, and content about dentistry may represent strategic resources to primary care teams regarding oral health, specifically the line of maternal and child care, from the field of public health. Literature review: journal articles from scientific basis of electronic data, and official documents from the Health Department were gathered to provide subsidies to the establishment of a comprehensive care plan for preg- 
nant women, taking into account the changes during this period. Final remarks: the documents evaluated indicate new reality, which demonstrates the work done by oral health professionals, permeated by the changes of the SUS, and by the systematic use of evidence regarding technique and dental materials, and yet, what such transformation might promote considering awareness about oral health education, qualification in care, and empowerment on the part of health professionals and families.

Keywords: Public health dentistry. Oral health. Pregnancy.

\section{Referências}

1. Brasil. Ministério da Saúde. Secretaria de Políticas de Saúde. Departamento de Atenção Básica: Programa Saúde da Família. Brasília DF: Ministério da Saúde; 2002.

2. Brasil. Ministério da Saúde. Grupo Hospitalar Conceição. Gerência de Saúde Comunitária. Atenção à saúde da criança de 0 a 12 anos. Porto Alegre: Ministério da Saúde; 2009.

3. Brasil. Ministério da Saúde. Secretaria de Atenção à Saúde. Departamento de Atenção Básica. Saúde Bucal. Brasília, DF: Ministério da Saúde; 2006.

4. Brasil. Ministério da Saúde. Secretaria de Atenção à Saúde. Departamento de Atenção Básica. Coordenação de Saúde Bucal. Projeto SB Brasil 2003 - condições de saúde bucal da população brasileira 2002-2003: resultados principais. Brasília DF: Ministério da Saúde; 2004.

5. Teixeira MCB. A dimensão cuidadora do trabalho de equipe em saúde e sua contribuição para a odontologia. Ciência \& Saúde Coletiva 2006; 11(1):45-51.

6. Brasil. Ministério da Saúde. Secretaria de Políticas de Saúde. Programa de Humanização no Pré-Natal e Nascimento (PHPN). Brasília DF: Ministério da Saúde; 2008.

7. Silva MV, Martelli PJL. Promoção em saúde bucal para gestantes: revisão da literatura. Odontologia Clín Científic 2009; 8(3):219-24.

8. Brasil. Ministério da Saúde. Secretaria de Atenção à Saúde. Departamento de Ações Programáticas Estratégicas. Área Técnica de Saúde da Mulher. Pré-natal e puerpério: atenção qualificada e humanizada - manual técnico. Brasília DF: Ministério da Saúde; 2005.

9. Magalhães AC, Rios D, Honório HM, Machado AM. Estratégias educativo-preventivas para a promoção de saúde bucal na primeira infância. Odontologia Clínica Científica 2009; $3(8): 245-9$

10. Finkler M, Oleiniski DMB, Ramos, FRS. Saúde bucal materno-infantil: um estudo de representações sociais com gestantes. Revista Texto \& Contexto em Enfermagem 2004; 13(3):360-8

11. Chiesa AM, Nascimento DDG, Braccialli LAD, Oliveira MAC. A formação de profissionais da saúde: aprendizagem significativa à luz da promoção da saúde. Cogitare Enfermagem 2007; 12(2):236-40.

12. Souza MT, Silva MD, Carvalho R. Revisão integrativa: o que e como fazer. Einstein 2010; 8:102-6.

13. Bastiani C, Cota ALS, Provenzano MGA, Fracasso MLC, Honório HM, Rios D. Conhecimento das gestantes sobre alterações bucais e tratamento odontológico durante a gravidez. Odontologia Clín Cientific 2010; 2(9):155-60.
14. Moimaz SAS, Rocha NB, Saliba O, Garbin CAS. O acesso de gestantes ao tratamento odontológico. Revista de Odontologia da Universidade Cidade de São Paulo 2007; 1(19):39-45.

15. Reis DM, Pitta DR, Ferreira HMB, de Jesus MCP, Moraes MEL, Soares MG. Educação em saúde como estratégia de promoção de saúde bucal em gestantes. Ciência \& Saúde Coletiva 2010; 15(1):269-276.

16. Domingues SM, Carvalho ACD, Narvai PC. Saúde bucal e cuidado odontológico: representações sociais de mães usuárias de um serviço público de saúde. Rev Bras Crescimento Desenvolv Hum 2008; 18(1):66-78.

17. Codato LAB, Nakama L, Júnior LC, Higasi MS. Atenção odontológica à gestante: papel dos profissionais de saúde. Ciência \& Saúde Coletiva 2011; 4(16):2297-2301.

18. Santos AM, Assis MMA. Da fragmentação à integralidade: construindo e (des)construindo a prática de saúde bucal no Programa de Saúde da Família (PSF) de Alagoinhas. Ciência \& Saúde Coletiva 2006; 1(11):53-61.

19. Silva FM, Xavier CB, Coppola MC, Lemes RS, Silva DS. Uso de anestésicos locais em gestantes. Robrac 2000; 9(28):4850 .

20. Poletto VC. Atendimento odontológico em gestantes: uma revisão da literatura. Stomatos 2008; 14(26):64-75.

21. Paiva LCA, Cavalcanti AL. Anestésicos locais em odontologia: uma revisão de literatura. Biol Health Sci 2005; 2(11):35-42.

22. Malamed SF. Manual de anestesia local. 5. ed. São Paulo: Elsevier; 2004.

23. Amadei SU, Carmo ED, Pereira AC, Silveira VAS, Rocha RF. Prescrição medicamentosa no tratamento odontológico de grávidas e lactantes. Rev Gaúcha Odontol 2011; 59:31-7.

24. Tirelli MC, Armonia PL, Tortamano N, Simone JL. Comportamento dos cirurgiões-dentistas quanto ao uso de antibióticos em pacientes gestantes: riscos e benefícios. Revista do Instituto de Ciências da Saúde 2001; 19(1):27-34.

25. Kulay JL, Kulay, MNC, Lapa AJ. Medicamentos na gravidez e lactação: guia prático. 2. ed. São Paulo: Manole, 2009.

26. Codato LAB, Nakama L, Melchior R. Percepções de gestantes sobre atenção odontológica durante a gravidez. Ciência \& Saúde Coletiva 2008; 13(3):1075-80.

27. Oliveira LSG, Nascimento DDG, Marcolino FF. Saúde bucal na Estratégia Saúde da Família: percepções de profissionais e cuidadores familiares. O Mundo da Saúde 2010; 1(34):6572 .

\section{Endereço para correspondência:}

Ana Cláudia Guterres Prestes

Rua Felipe Camarão, 717, apto. 61, Bairro

Bom Fim

90.035-141 Porto Alegre - RS

E-mail: acprestes@gmail.com

Recebido: 05/06/2013. Aceito: 16/07/2013. 